\title{
Clinical data and molecular analysis of Mycobacterium tuberculosis isolates from drug-resistant tuberculosis patients in Goiás, Brazil
}

\author{
Sueli Lemes de Ávila Alves ${ }^{1,2}$, Fabiana Sarcinelli Metzker ${ }^{1}$, \\ João Alves de Araújo-Filho',3, Ana Paula Junqueira-Kipnis ${ }^{1}$, André Kipnis ${ }^{1 /+}$ \\ ${ }^{1}$ Instituto de Patologia Tropical e Saúde Pública, Universidade Federal de Goiás, Rua 235/1a Av. s/n, 746050-050 Goiânia, GO, Brasil \\ ${ }^{2}$ Laboratório Central de Saúde Pública Dr. Giovanni Cysneiros, Goiânia, GO, Brasil \\ ${ }^{3}$ Hospital de Doenças Tropicais Dr Anuar Auad, Goiânia, GO, Brasil
}

\begin{abstract}
Drug resistance is one of the major concerns regarding tuberculosis (TB) infection worldwide because it hampers control of the disease. Understanding the underlying mechanisms responsible for drug resistance development is of the highest importance. To investigate clinical data from drug-resistant TB patients at the Tropical Diseases Hospital, Goiás (GO), Brazil and to evaluate the molecular basis of rifampin (R) and isoniazid (H) resistance in Mycobacterium tuberculosis. Drug susceptibility testing was performed on 124 isolates from 100 patients and 24 isolates displayed resistance to $R$ and/or H. Molecular analysis of drug resistance was performed by partial sequencing of the $\mathrm{rpoB}$ and $\mathrm{katG}$ genes and analysis of the inhA promoter region. Similarity analysis of isolates was performed by 15 loci mycobacterial interspersed repetitive unit-variable number tandem repeat (MIRU-VNTR) typing. The molecular basis of drug resistance among the 24 isolates from 16 patients was confirmed in 18 isolates. Different susceptibility profiles among the isolates from the same individual were observed in five patients; using MIRU-VNTR, we have shown that those isolates were not genetically identical, with differences in one to three loci within the 15 analysed loci. Drug-resistant TB in GO is caused by M. tuberculosis strains with mutations in previously described sites of known genes and some patients harbour a mixed phenotype infection as a consequence of a single infective event; however, further and broader investigations are needed to support our findings.
\end{abstract}

Key words: MDR-TB - MIRU-VNTR - katG - rpoB

Tuberculosis (TB) is a major world health problem with an estimated 9.4 million incidents of TB cases occurring globally in 2009 (equivalent to 137 cases per 100,000 inhabitants). Of the 9.4 million cases, an estimated 1.0-1.2 million (11-13\%) were human immunodeficiency virus (HIV)-positive. Although the American continent is responsible for only $3 \%$ of the total TB burden, Brazil continues to be one of the 22 countries worldwide that contributes to the TB burden and accounts for $81 \%$ of all estimated cases (WHO 2010).

One of the most important challenges faced by TB control programs is the emergence and dissemination of drug-resistant TB worldwide, especially multidrugresistant TB (MDR-TB) and extensively drug-resistant TB (XDR-TB). MDR-TB is caused by Mycobacterium tuberculosis that is resistant to at least rifampin $(\mathrm{R})$ and isoniazid ( $\mathrm{H})$, and XDR-TB is defined as M. tuberculosis that is resistant to $\mathrm{R}, \mathrm{H}$, a fluoroquinolone and at least one of three injectable second-line drugs (i.e., capreomycin, kanamycin and amikacin) (Raviglione \& Smith 2007). Drug resistance generally emerges due to the long period

Financial support: CNPq (569257/2008-5, 301198/2009-8, 300132/ 2008-5), FUNAPE-UFG

+ Corresponding author: akipnis@iptsp.ufg.br

Received 7 January 2011

Accepted 6 June 2011 of treatment necessary for TB that favours poor therapy adherence, especially when therapy is without clinical supervision (Araújo-Filho et al. 2008, WHO 2008, Dye 2009, Santos et al. 2010). Of the utmost importance is the fact that MDR-TB and XDR-TB necessitate longer periods of treatment, usually requiring a hospital facility with biosafety concerns, in addition to the high mortality rate of XDR-TB (Curry 2008, WHO 2008).

Traditional drug resistance analysis is based on culture methods, which take a long time to produce results, demanding both labour and biosafety concerns. However, molecular approaches that rapidly detect mutations in specific genes have shown a good correlation with the results of culture susceptibility testing (ST), but these methods are not accessible in developing regions (Palomino 2009, Boehme et al. 2010). Thus, it is crucial to detect resistance to $\mathrm{R}$ because it is a good predictive marker of MDR-TB (Martin \& Portaels 2007, Curry 2008). Early discovery of resistance allows for immediate adoption of the appropriate treatment regimens and, consequently, higher rates of treatment success.

The molecular characterisation of $M$. tuberculosis strains by DNA fingerprinting methods during the course of infection has revealed different genetic profiles in isolates from closely related infected individuals and within the same host. Those observations could be explained by mixed infections or microevolution of the infecting pathogens (Braden et al. 2001, Shamputa et al. 2006).

To better understand the microbiological aspects of drug-resistant TB infections, isolates from patients with $\mathrm{TB}$ resistant to $\mathrm{R}$ and/or $\mathrm{H}$ were evaluated. The clinical 
and the phenotypic resistance profiles were evaluated with emphasis on the analysis of mutations in the rpoB, catalase gene $(\mathrm{kat} G)$ and $i n h A$ genes. Additionally, we investigated the genetic relationship among strains with different phenotypes from the same TB patient.

\section{PATIENTS, MATERIALS AND METHODS}

Patient enrolment and clinical data collection - This work is a descriptive study using a convenience sample size. During the period of September 2005-December 2007, 410 cultures were identified as M. tuberculosis based on traditional biochemical tests at Central Laboratory of Public Health of Goiás (LACEN-GO). ST was performed in $124 \mathrm{M}$. tuberculosis isolates from $100 \mathrm{pa}-$ tients following a physician's request and 24 of the isolates demonstrated resistance to at least one of the two drugs, $\mathrm{H}$ and $\mathrm{R}$; these isolates were recovered from 16 patients. The patients were recruited and agreed to participate by signing an informed consent form. Clinical evaluations of the enrolled patients were obtained from the clinical charts at the Dr Anuar Auad Tropical Diseases Hospital, a reference centre for the treatment of infectious diseases. The patients' outcome was followed up until December of 2010 (Table I).

M. tuberculosis isolation, ST and DNA extraction M. tuberculosis isolates were obtained from Lowenstein Jensen cultures of sputum, lymph node secretion and/ or cerebrospinal fluid samples. ST for R, H, streptomycin (S), ethionamide (Et), and ethambutol (E) were performed according to Canetti et al. (1969). Isolated strains were stored in Sauton media with $10 \%$ glycerol at $-80^{\circ} \mathrm{C}$.

Chromosomal DNA was extracted according to van Embden et al. (1993). DNA extractions were analysed by $0.8 \%$ agarose gel electrophoresis stained with $0.5 \mu \mathrm{g} / \mathrm{mL}$ of ethidium bromide, visualised on a Gel Doc System (Bio-Rad) and stored at $-20^{\circ} \mathrm{C}$.

Partial amplification and sequencing of the rpoB and katG genes - Chromosomal DNA, obtained as described, was further diluted 10 times and $2 \mu \mathrm{L}$ of each diluted DNA sample was used for the polymerase chain reaction (PCR) reactions. Partial amplification of the RNA polymerase gene $B(r p o B)$ was performed using the pair of primers described by Siddiqi et al. (2002): rpoB1 (forward) 5'GGGAGCGGATGACCACCC3' and rpoB2 (reverse) 5'GCGGTACGACGGCGTTTCGATGAAC3'. Similarly, $k a t G$ was partially amplified using the pair of primers described by (Marttila et al. 1996): kat G1 (forward) 5'GAAACAGCGGCGCTGATCGT3' and katG2 (reverse) 5'GTTGTCCCATTTCGTCGGGG3'. The PCR reactions contained $0.1 \eta$ mol of each primer for the $r p o B$ or $k a t G$ genes, $0.2 \mu \mathrm{M}$ of dNTPs and one unit of Taq DNA polymerase (Invitrogen) in a final volume of $30 \mu \mathrm{L}$. Amplification was performed in a thermocycler (MJ-Biocyler) programmed with the following conditions: an initial denaturation step of $95^{\circ} \mathrm{C}$ for $3 \mathrm{~min}$ followed by 35 cycles of denaturation at $92^{\circ} \mathrm{C}$ for $40 \mathrm{sec}$, annealing at $56^{\circ} \mathrm{C}$ for $40 \mathrm{sec}$, and extension at $72^{\circ} \mathrm{C}$ for $1 \mathrm{~min}$ with a final extension cycle of $72^{\circ} \mathrm{C}$ for $7 \mathrm{~min}$. As a positive control, H37Rv M. tuberculosis (ATCC 27294) DNA was included. Five microlitres of the PCR products were analysed by $1.5 \%$ agarose gel electrophoresis stained with $0.5 \mu \mathrm{g} / \mathrm{mL}$ of ethidium bromide and visualised on a Gel Doc System (Bio-Rad). The expected sizes of the PCR products for the $k a t G$ and $r p o B$ genes were 209 and 332 base pairs (bp), respectively. The remaining PCR products were precipitated with isopropanol, resuspended in MiliQ grade water and sequenced using each primer from the PCR reactions. Sequencing reactions were performed with the BigDye Terminator Kit (Applied Biosystems) according to the manufacturer instructions and run on the ABI3130 Genetic Analyzer (Applied Biosystems). The Sequencing Analysis software package (version 3.3, Applied Biosystems) was used to analyse the data quality. Sequences were compared to the H37Rv strain sequences (Gene Bank accessions BX842574 and X68081) using ClustalX (version 2.0) and BioEdit (version 7.0) software for mutation identification. Visualised mutations were double-checked using DNA STAR version 5.1 software.

Analysis of mutations in the promoter of the inh A gene by real-time PCR (RT-PCR) - The samples were analysed for mutations at the ribosome-binding site in the promoter of the mabA-inhA operon by RT-PCR. The primer pair mabAF (5'CGAAGTGTGCTGAGTCACACCG3') and inhAR-mut (5'AGTCACCCCGACAACCTATTA3'), described by Herrera-León et al. (2005), was used to amplify a 146-bp fragment of the mutated region, while the primer pair mabAF and inhARwt (5'AGTCACCCCGACAACCTATCG3') was used in a separate RT-PCR to amplify a 146-bp fragment of the wild-type region. SYBR Green Supermix (Bio-Rad) was used for RT-PCR. RT-PCR was performed in an IQ5 thermocycler (Bio-Rad) at $94^{\circ} \mathrm{C}$ for $1 \mathrm{~min}, 65^{\circ} \mathrm{C}$ for $1 \mathrm{~min}$ and $72^{\circ} \mathrm{C}$ for $1 \mathrm{~min}$ for 35 cycles. After amplification was complete, a final melting curve was recorded while the reaction mixture was slowly heated from $62-95^{\circ} \mathrm{C}$. Mutations were identified when amplification was detected with the mutant primer, but not with the wild-type primer.

Mycobacterial interspersed repetitive unit-variable number tandem repeat (MIRU-VNTR) typing - Amplification of 15 loci $(580,2996,802,960,1644,3192,424$, 577, 2165, 2401, 3690, 4156, 2163b, 1955 and 4052) was performed according to (Supply et al. 2006). The PCR products were analysed on a $2 \%$ agarose gel stained with ethidium bromide and visualised on a Gel Doc System (Bio-Rad). Each gel contained 100-bp ladder standards (Invitrogen) and the number of bp in the target VNTR loci was estimated using Quantity One (Bio-Rad) software. The number of repetitions of various MIRU-VNTR loci of each strain were determined and regarded as an allele profile. DNA from M. tuberculosis H37Rv (ATCC 27294) was included as a positive control for each amplification reaction. A phylogenetic tree was constructed by entering the allele profiles into the MIRU-VNTR plus database (Allix-Béguec et al. 2008) using the unweighted pair group method with an arithmetic mean algorithm.

Ethics - The Ethical Committee of Federal University of Goiás approved this study under the protocol UFG-006/2005. 


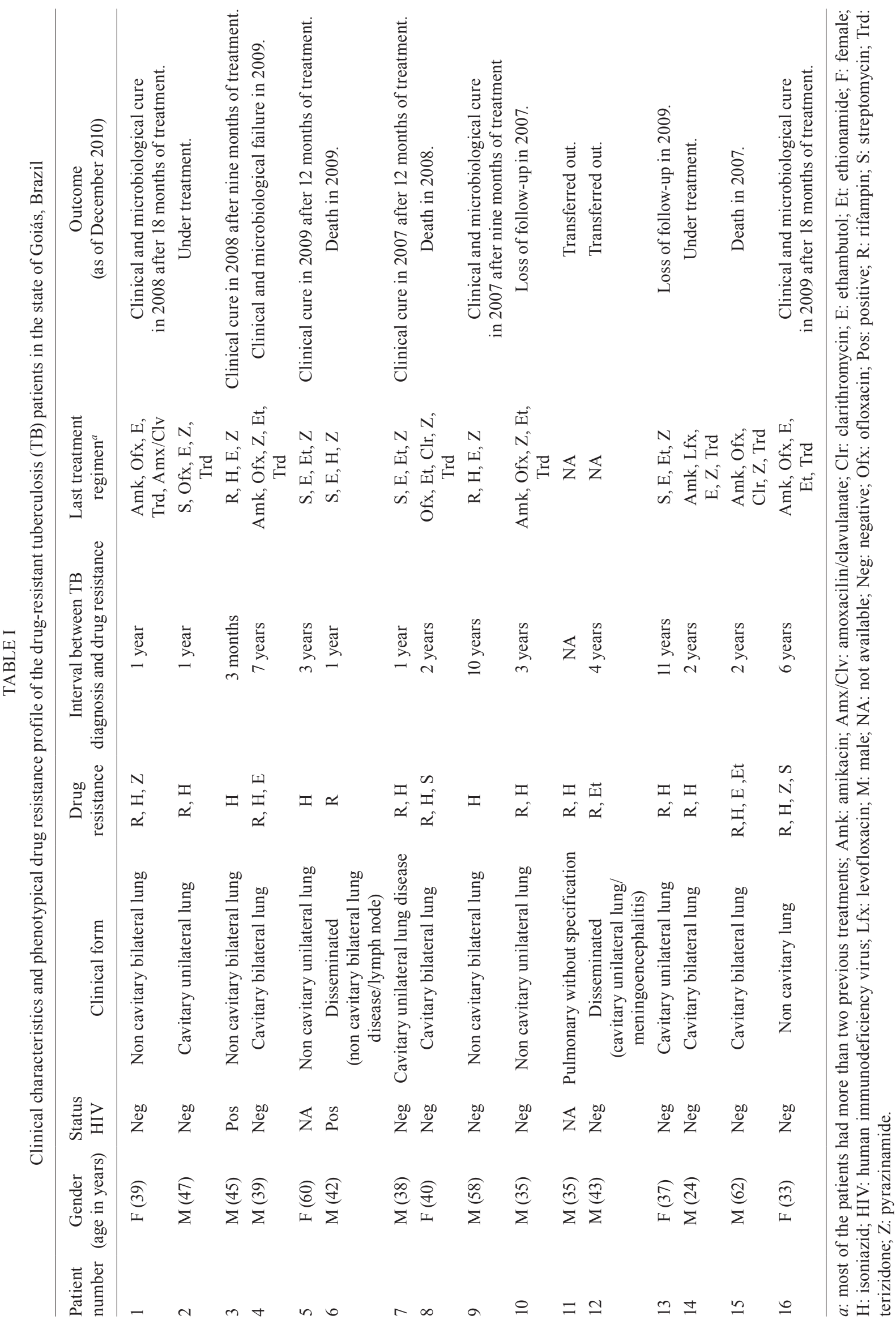




\section{RESULTS}

During the period of September 2005-December 2007, 410 cultures were identified as M. tuberculosispositive based on traditional biochemical tests performed at LACEN-GO. ST was performed on $124 \mathrm{M}$. tuberculosis isolates from $100 \mathrm{~TB}$ patients following a physician's request; 24 (19.35\%) of the isolates obtained from 16 patients presented with resistance to at least one of the two drugs, $\mathrm{H}$ and $\mathrm{R}$.

The individuals with $M$. tuberculosis isolates resistant to $\mathrm{H}$ and/or $\mathrm{R}$ were evaluated and their clinical characteristics are presented in Table I. Eleven patients were male $(68.7 \%)$ and the mean age was 42.3 years old (range 24-62 years old). Among the comorbidities presented by the patients, HIV and leprosy were present in $12.5 \%$ and $6.3 \%$ of the cases, respectively.

The diagnosis of drug-resistant TB occurred at three132 months (average of 42.9 months) after the TB diagnosis. In addition to $\mathrm{R}$ and $\mathrm{H}$ resistance, phenotypic resistance to $\mathrm{E}, \mathrm{S}$ and $\mathrm{Et}$ was also detected (Table I). Due to the small number of individuals investigated, no predisposing factor was statistically associated with the development of monodrug and/or multidrug resistance (data not shown), although one of the patients had a confirmed contact with an MDR-TB index case.

Lung cavity was the main characteristic lesion present in nine $(56.3 \%)$ patients. A bilateral lung commitment was observed in eight patients. Disseminated TB was present in two patients; one was HIV-positive and the other was infected with Mycobacterium leprae with chronic use of prednisone and thalidomide. None of the HIV-positive patients presented with cavitary lung disease.

Among the studied patients, only six were clinically cured, three of which also had negative cultures for acid-fast bacilli. The clinical follow-ups of four of the patients were interrupted due to their transfer to another care centre or to treatment abandonment; consequently, the final outcome for these patients remains unknown. Three deaths occurred. Three patients remained under treatment until the end of this study, one of which had acid-fast bacilli-positive sputum.

During the course of the treatment, some patients received at least four drugs with certain or almost certain effectiveness based on drug susceptibility tests and individual tolerability (Table I). The others patients received the standard regimens for re-treatment/failure or monoresistant TB according to the current guidelines of the Brazilian Ministry of Health (MS/SVS 2010).

Ten patients $(62.5 \%)$ had MDR M. tuberculosis isolates, while monoresistance to $\mathrm{H}$ was observed in only five patients $(31.3 \%)$ and one $(6.3 \%)$ had an isolate with monoresistance to R. Five patients $(31.3 \%)$ had more than one culture sample obtained at different time points during the course of the disease; these patients had samples taken at different times due to the failure of the sputum to become negative during chemotherapy (Table II). Interestingly, the ST profile of the different isolates from the same patient varied significantly. For example, in patient 4 and 8, their first isolated cultures had an MDR phenotype, while posterior isolates presented with monoresistance to R. Inversely, and more understandable, the first isolate from patient 13 was resistant to $\mathrm{H}$ and the second culture that was isolated eight months later presented with an MDR phenotype.

The differences observed in ST among the different isolates from the same patient prompted us to investigate the molecular basis of drug resistance. As shown in Table II, all but one of the $17 \mathrm{M}$. tuberculosis isolates resistant to $\mathrm{R}$ had a mutation in previously described regions of the rрoB gene. Similarly, most $M$. tuberculosis isolates (11 out of 17) resistant to $\mathrm{H}$ presented with mutations in the analysed regions of either the kat $G$ or inhA genes.

To further investigate the genetic relatedness of the isolates, we performed a similarity analysis based on MIRU-VNTR typing (Figure). The isolates from the different TB patients were not genetically related. The isolates obtained from the same patient at different periods of time presented a unique, but closely associated, MIRU-VNTR type. The isolates from the same patient showed allele differences in one-three different loci. Only patient 4 presented with two isolates (2 out of 4 ) with an identical MIRU-VNTR type.

\section{DISCUSSION}

In the present study, we demonstrated that the molecular basis of the $\mathrm{R}$ and $\mathrm{H}$ resistance of M. tuberculosis isolated from the studied patients was attributed to known mutations in the $r p o B$ and kat $G$ genes and in the promoter region of the inh $A$ gene. The isolates from the same patient had different drug susceptibility profiles; genetic analyses of those isolates using MIRU-VNTR revealed that they were not genetically identical, with one-three loci differences.

Evaluating the clinical profile of the enrolled TB patients, as shown elsewhere (Drobeniewski et al. 2002, Barroso et al. 2003, Araújo-Filho et al. 2008, WHO 2008), it was observed that the long period of time between the first diagnosis of $\mathrm{TB}$ and the resistance diagnosis is probably the result of poor clinical practices, such as not routinely performing culture and susceptibility tests. It is also important to point out that the previous TB treatment was not supervised because at the time the patient enrolled, direct observed treatment was not adopted. Only recently, there was a change in the Brazilian guidelines recommending culture and susceptibility tests in all re-treatment cases, in cases with confirmed contact with MDR-TB patients, in cases where sputum remains positive at the second month of treatment and in cases with treatment failure (MS/SVS 2010).

We have previously shown that in Goiás (GO) there is an unexpected high rate of resistance among naïve treated patients $(13.6 \%)$, suggestive of primary drug resistance (Santos et al. 2010). In this study, two patients presented clinical evidence for primary drug resistance (i.e., contact with MDR-TB and a short interval for resistance development). However, the long period for resistance development/detection observed in the present study also suggests the possibility that the majority of drug-resistant cases are secondary cases in which the drug resistance emerged after inadequate previous treatments (Martin \& Portaels 2007, Araújo-Filho et al. 2008, Curry 2008). 
TABLE II

Drug susceptibility phenotype of the isolated strains and molecular analysis of mutations in kat $\mathrm{G}$, rpoB and inhA genes of Mycobacterium tuberculosis

\begin{tabular}{|c|c|c|c|c|c|c|}
\hline Patient $^{a}$ & Collection date & SS & ST & $k a t G^{b}$ & $\operatorname{inh} A^{c}$ & $r p o B^{b}$ \\
\hline 1 & 29 December 2006 & $\mathrm{Sp}$ & $\mathrm{H}+\mathrm{R}$ & 315 ser $\rightarrow$ thr & ND & 456 ser $\rightarrow$ leu \\
\hline 2 & 2 January 2006 & $\mathrm{Sp}$ & $\mathrm{H}+\mathrm{R}$ & $315 \mathrm{ser} \rightarrow \mathrm{thr}$ & ND & 456 ser $\rightarrow$ leu \\
\hline 3 & 23 January 2007 & $\mathrm{Sp}$ & $\mathrm{H}$ & $\begin{array}{l}315 \mathrm{ser} \rightarrow \mathrm{thr} \\
297 \mathrm{gly} \rightarrow \text { gly }\end{array}$ & ND & ND \\
\hline $4 \mathrm{~A}$ & 30 August 2005 & $\mathrm{Sp}$ & $\mathrm{H}+\mathrm{R}$ & $\mathrm{NM}$ & NM & 456 ser $\rightarrow$ leu \\
\hline 4B & 10 March 2006 & $\mathrm{Sp}$ & $\mathrm{H}+\mathrm{R}$ & NM & NM & 456 ser $\rightarrow$ leu \\
\hline $4 \mathrm{C}$ & 17 November 2006 & $\mathrm{Sp}$ & $\mathrm{R}$ & ND & ND & 456 ser $\rightarrow$ leu \\
\hline $4 \mathrm{D}$ & 12 April 2007 & $\mathrm{Sp}$ & $\mathrm{R}$ & ND & ND & 456 ser $\rightarrow$ leu \\
\hline 5 & 2 April 2007 & $\mathrm{Sp}$ & $\mathrm{H}$ & 297 gly $\rightarrow$ gly & ND & ND \\
\hline $6 \mathrm{~A}$ & 3 June 2007 & $\mathrm{LN}$ & $\mathrm{R}$ & ND & ND & 451 his $\rightarrow$ tyr \\
\hline $6 \mathrm{~B}$ & 19 June 2007 & $\mathrm{LN}$ & $\mathrm{R}$ & ND & ND & 451 his $\rightarrow$ tyr \\
\hline $6 \mathrm{C}$ & 13 December 2007 & $\mathrm{Sp}$ & $\mathrm{R}$ & ND & ND & 451 his $\rightarrow$ tyr \\
\hline 7 & 13 July 2006 & $\mathrm{Sp}$ & $H+R$ & $315 \mathrm{ser} \rightarrow$ thr & ND & 447 ser $\rightarrow$ leu \\
\hline $8 \mathrm{~A}$ & 31 July 2006 & $\mathrm{Sp}$ & $H+R$ & NM & NM & 456 ser $\rightarrow$ leu \\
\hline $8 \mathrm{~B}$ & 31 August 2006 & $\mathrm{Sp}$ & $\mathrm{R}$ & ND & ND & 456 ser $\rightarrow$ leu \\
\hline 9 & 23 August 2006 & $\mathrm{Sp}$ & $\mathrm{H}$ & NM & NM & ND \\
\hline 10 & 28 October 2007 & $\mathrm{Sp}$ & $\mathrm{H}+\mathrm{R}$ & NM & NM & NM \\
\hline 11 & 28 September 2006 & $\mathrm{Sp}$ & $\mathrm{H}+\mathrm{R}$ & NM & NM & 456 ser $\rightarrow$ leu \\
\hline $12 \mathrm{~A}$ & 6 October 2006 & $\mathrm{CSF}$ & $\mathrm{H}$ & $\mathrm{NM}$ & Yes & ND \\
\hline $12 \mathrm{~B}$ & 23 November 2006 & $\mathrm{Sp}$ & ND & NM & Yes & $456 \mathrm{ser} \rightarrow$ leu \\
\hline $13 \mathrm{~A}$ & 10 February 2006 & $\mathrm{Sp}$ & $\mathrm{H}$ & 315 ser $\rightarrow$ asn & ND & ND \\
\hline $13 \mathrm{~B}$ & 4 October 2006 & $\mathrm{Sp}$ & $\mathrm{H}+\mathrm{R}$ & 315 ser $\rightarrow$ asn & ND & $456 \mathrm{ser} \rightarrow$ leu \\
\hline 14 & 17 November 2006 & $\mathrm{Sp}$ & $\mathrm{H}+\mathrm{R}$ & NM & Yes & 456 ser $\rightarrow$ leu \\
\hline 15 & 28 November 2006 & $\mathrm{Sp}$ & $\mathrm{H}+\mathrm{R}$ & NM & Yes & 456 ser $\rightarrow$ leu \\
\hline 16 & 8 December 2006 & $\mathrm{Sp}$ & $\mathrm{H}$ & 315 ser $\rightarrow$ asn & ND & ND \\
\hline
\end{tabular}

$a$ : each number represents one patient and letters corresponds to different isolates from the same patient; $b$ : mutations found by partial gene sequencing; $c$ : mutation detected by real-time polymerase chain reaction; CSF: cerebrospinal fluid; H: isoniazide; LN: lymph node; NM: no mutations; ND: not done; R: rifampin; Sp: sputum; SS: sample source; ST: susceptibility testing.

Potential risk factors for MDR-TB development are the presence of bilateral and extensive pulmonary cavities (Barroso et al. 2003, Kaplan et al. 2003); our data corroborates with these reports because a predominance of bilateral and cavitary pulmonary disease was observed in the majority of the patients (Table I and data not shown). Thus far, it has not been shown if and how cavities induce resistance. Timm et al. (2003) have shown that the cavity imposes an environment pressure, such as oxygen and iron deprivation, that leads to an increase in the metabolic changes of M. tuberculosis. It is possible that these metabolic changes could be associated with higher rates of mutations (Timm et al. 2003).

The finding of diverse drug susceptibility profiles observed in the different $M$. tuberculosis isolates from the same patient at different time points could be explained by the development of resistance to additional drugs (Johnson et al. 2006, Bergval et al. 2009); this could be the case for patient 13 , for whom the first isolate presented monoresistance to $\mathrm{H}$ and the second isolate obtained eight months later acquired an additional resistance to $\mathrm{R}$, confirmed by mutation in codon 456 of the rpoB gene.

The evolution of drug resistance patterns observed in the M. tuberculosis isolates from patients 4 and 8 was unexpected, as it went from an MDR to a monoresistance phenotype; combining this observation with the genetic profile of the isolates from patients 4 and 8 , it is interesting to point out that while the first two isolates from patient 4 were identical, the next two isolates had a single allele difference in loci 580 and 4156 . The interval of time over the sample collection period (5-9 months) could have favoured this event. In contrast, the isolates from patient 8 were more divergent (2 loci differences) than the isolates from patient 4 , even though those isolates were obtained only one month apart. Two hypotheses could be formulated to explain these changes: first, a mutation could reverts the susceptibility of $M$. tuberculosis to $\mathrm{H}$ or, second, the patients could harbour mixed bacterial populations, for example, MDR and monoresistant strains that could have been artificially 


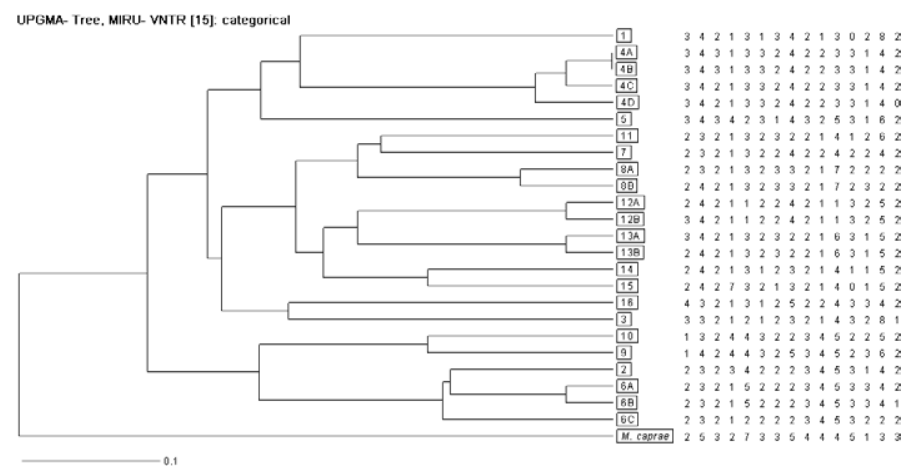

Dendogram of similarity analysis of the 24 isolates included in this study. Isolates from the same patient have the same number with different letters. The bar indicates genetic distance calculated by the unweighted pair group method with an arithmetic mean method. Isolate M. caprae mycobacterial interspersed repetitive unit-variable number tandem repeat (MIRU-VNTR) profile from MIRU-VNTR plus database was included as outlier strain. Allele numbers for each locus are presented in the following order of loci from left to right: 424, 577, 580, 802, 960, 1644, 1955, 2163b, 2165, 2401, 2996, 3192, 3690, 4052 and 4156.

missed during laboratory ST due to culture manipulations (Matthys et al. 2009, Richardson et al. 2009). Mutation reversion has been recently reported for MDR $M$. tuberculosis (Richardson et al. 2009) in a patient receiving chemotherapy without $\mathrm{R}$ and $\mathrm{H}$; although we could not prove this was the case for our results, it is an unlikely explanation because the patients were receiving $\mathrm{H}$ therapy during the sampling period (data not shown).

TB infection with a heterogeneous $M$. tuberculosis population can be caused by a re-infection event or by an evolutionary genetic variation of a single infection event (Small et al. 1993, Andrews et al. 2008). To address this question, we performed MIRU-VNTR typing to analyse the genetic relatedness of the different $M$. tuberculosis isolates from the same individual. We demonstrated here that $M$. tuberculosis isolates from the same patient had closely related MIRU-VNTR types, which suggested that they originated from a common strain, supporting the theory of mutational changes during the course of infection and rejecting the possibility of reinfection. Additionally, it has been proposed that drug resistance imposes a fitness cost to bacteria (Gagneux et al. 2006); if this is the case, this finding could explain the persistence of the heterogeneous bacterial population in those individuals and, during sampling times, a particular strain with or without drug resistance would be preferentially selected.

The present paper had a small sample size and this fact could be the consequence of several factors, including a lack of awareness of the assistant physicians that ST should be prescribed. It is important to stress that all available drug-resistant isolates from GO during the period of 2005 and 2007 were evaluated.

We concluded that drug-resistant TB in GO is caused by $M$. tuberculosis strains with mutations in the rpoB and $k a t G$ genes and in the promoter region of the $i n h A$ gene. In addition, some patients harbour a mixed phenotype/ genotype of M. tuberculosis populations that probably originated from a single infective event and evolved during disease progression; however, further and broader investigations are needed to support our findings.

\section{ACKNOWLEDGEMENTS}

To Lorena Cristina Santos, Ivanísio Gomes de Santana, Héberson Alves de Oliveira, and Maria Gasparina de Carvalho Alves, for technical assistance.

\section{REFERENCES}

Allix-Béguec C, Harmsen D, Weniger T, Supply P, Niemann S 2008. Evaluation and user-strategy of MIRU-VNTR plus, a multifunctional database for on line analysis of genotyping data and phylogenetic identification of Mycobacterium tuberculosis complex isolates. J Clin Microbiol 46: 2692-2699.

Andrews JR, Gandhi NR, Moodley P, Shah NS, Bohlken L, Moll AP, Pillay M, Friedland G, Sturm AW 2008. Exogenous reinfection as a cause of multidrug-resistant and extensively drug-resistant tuberculosis in rural South Africa. J Infec Dis 198: 1582-1589.

Araújo-Filho JA, Vasconcelos-Jr AC, Sousa EM, Silveira C, Sousa PTP, Severo KA, Vieira LF, Kipnis A, Junqueira-Kipnis AP 2008. Multidrug-resistant tuberculosis: case reports study in a central state of Brazil. Braz J Infecti Dis 12: 94-98.

Barroso EC, Mota RMS, Morais MFM, Campelo CL, Barroso JB, Rodrigues JLN 2003. Fatores associados aos tratamentos inadequados em portadores de tuberculose multirresistente. J Pneumo 29: 350-357.

Bergval IL, Schuitema ARJ, Klatser PR, Anthony RM 2009. Resistant mutants of Mycobacterium tuberculosis selected in vitro do not reflect the in vivo mechanism of isoniazid resistance. $J$ Antimicrob Chemother 64: 515-523.

Boehme CC, Nabeta P, Hillemann D, Nicol MP, Shenai S, Krapp F, Allen J, Tahirli R, Blakemore R, Rustomjee R, Milovic A, Jones M, O'Brien SM, Persing DH, Ruesch-Gerdes S, Gotuzzo E, Rodrigues C, Alland D, Perkins MD 2010. Rapid molecular detection of tuberculosis and rifampin resistance. $N$ Engl J Med 363: 1005-1015.

Braden CRGP, Morlock CL, Woodley KR, Johnson AC, Colombel MD, Cave Z, Yang SE, Valway IMO, Crawford JT 2001. Simultaneous infection with multiple strains of Mycobacterium tuberculosis strains. Clin Infect Dis 33: 42-47.

Canetti G, Fox W, Khomenko A, Mahler HT, Menon NK, Mitchison DA, Rist N, Smelev NA 1969. Advances in techniques of testing mycobacterial drug sensitivity and use of sensitivity tests in tuberculosis control programmes. Bull World Health Organ 4: 21-43. 
Curry FJ 2008. Drug-resistant tuberculosis: a survival guide for clinicians, 2nd ed., National Tuberculosis Centre/California Department of Public Health, San Francisco, 266 pp.

Drobeniewski F, Eltringham I, Graham C, Magee JG, Watt B 2002. A national study of clinical and laboratory factors affecting the survival of patients with multiple drug resistant tuberculosis in the UK. Thorax 57: 810-816.

Dye C 2009. Doomsday postponed? Preventing and reversing epidemics of drug-resistant tuberculosis. Nat Rev Microbiol 7: 81-87.

Gagneux S, Long CD, Small PM, Van T, Schoolnik GK, Bohannan BJ 2006. The competitive cost of antibiotic resistance in Mycobacterium tuberculosis. Science 312: 1944-1946.

Herrera-León L, Molina T, Saíz P, Sáez-Nieto JA, Jiménez MS 2005. New multiplex PCR for rapid detection of isoniazid resistant $M y$ cobacterium tuberculosis clinical isolates. Antimicrob Agents Chemother 49: 144-147.

Johnson R, Streicher EM, Louw GE, Warrewn M, Helden Pdvan, Victor TC 2006. Drug resistance in Mycobacterium tuberculosis. Curr Issues Mol Biol 8: 97-112.

Kaplan GL, Post FA, Moreira AL, Wainwright H, Kreiswirth BN, Tanverdi M, Mathema B, Ramaswamy SV, Walther G, Steyn LM, Barry III CE, Bekker L 2003. Mycobacterium tuberculosis growth at the cavity surface: a microenvironment with failed immunity. Infect Immun 71: 7099-7108.

Martin A, Portaels F 2007. Drug resistance and drug resistance detection. In JC Palomino, SC Leão, V Ritacco (eds.), Tuberculosis - from basic science to patient care. Available from: tuberculosistextbook.com, p. 635-660.

Marttila HJ, Soini H, Huovinen P, Viljanen MK 1996. KatG mutations in isoniazid resistant Mycobacterium tuberculosis isolates recovered from finish patients. Antimicrob Agents Chemother 40: 2187-2189.

Matthys F, Rigouts L, Sizaire V, Vezhnina N, Lecoq M, Golubeva V, Portaels F, Van der Stuyft P, Kimerling M 2009. Outcomes after chemotherapy with WHO category II regimen in a population with high prevalence of drug resistant tuberculosis. PLoS ONE 4: e7954.

MS/SVS - Ministério da Saúde/Secretaria de Vigilância em Saúde, Brasil 2010. [accessed 6 January 2010]. Manual de recomendações para o controle da tuberculose no Brasil. Available from: portal.saude.gov.br/portal/arquivos/pdf/manual_de_recomendacoes_controle_tb_novo.pdf.

Palomino JC 2009. Molecular detection, identification and drug resistance detection in Mycobacterium tuberculosis. FEMS Immunol Med Microbiol 56: 103-111.
Raviglione MC, Smith IM 2007. XDR tuberculosis - implications for global public health. $N$ Engl J Med 356: 656-659.

Richardson ET, Lin SYG, Pinsky BA, Desmond E, Banaei N 2009. First documentation of isoniazid reversion in Mycobacterium tuberculosis. Int J Tuberc Lung Dis 13: 1347-1354.

Santos LC, Bousquet HM, Pereira AM, Junqueira-Kipnis AP, Kipnis A 2010. A high prevalence of resistance in new tuberculosis cases of midwestern Brazil. Infect Genet Evol 10:1052-1057.

Shamputa IC, Jugheli L, Sadradze N, Willery E, Portaels F, Supply P, Rigouts L 2006. Mixed infection and clonal representativeness of a single sputum sample in tuberculosis patients from a penitentiary hospital in Georgia. Respir Res 7: 99.

Siddiqi N, Shamim M, Hussain S, Choudhary RK, Ahmed N, Prachee, Banerjee S, Savithri GR, Alam M, Pathak N, Amin A, Hanief M, Katoch VM, Sharma SK, Hasnain SE 2002. Molecular characterization of multidrug-resistant isolates of Mycobacterium tuberculosis from patients in North India. Antimicrob Agents Chemother 46: 443-450.

Small PM, Shafer RW, Hopewell PC, Singh SP, Murphy MJ, Desmond E, Sierra MF, Schoolnik GK 1993. Exogenous reinfection with multidrug-resistant Mycobacterium tuberculosis in patients with advanced HIV infection. $N$ Engl J Med 328: 1137-1144.

Supply P, Allix C, Lesjean S, Cardoso-Oelemann M, Rüsch-Gerdes S, Willery E, Savine E, Haas P, van Deutekom H, Roring S, Bifani P, Kurepina N, Kreiswirth B, Sola C, Rastogi N, Vatin V, Gutierrez MC, Fauville M, Niemann S, Skuce R, Kremer K, Locht C, van Soolingen D 2006. Proposal for standardization of optimized mycobacterial interspersed repetitive unit-variable-number tandem repeat typing of Mycobacterium tuberculosis. J Clin Microbiol 44: 4498-4510.

Timm J, Post FA, Bekker LG, Walther GB, Wainwright HC, Manganelli R, Chan WT, Tsenova L, Gold B, Smith I, Kaplan G, McKinney JD 2003. Differential expression of iron, carbon and oxygen-responsive mycobacterial genes in the lungs of chronically infected mice and tuberculosis patients. PNAS 100: 14321-14326.

van Embden JD, Cave MD, Crawford JT, Dale JW, Eisenach KD, Gicquel B, Hermans P, Martin C, McAdam R, Shinnick TM 1993. Strain identification of Mycobacterium tuberculosis by DNA fingerprinting: recommendations for a standardized methodology. J Clin Microbiol 31: 406-409.

WHO - World Health Organization 2008. Guidelines for the programmatic management of drug-resistant tuberculosis. Emergency update 2008, WHO, Geneva, $272 \mathrm{pp}$.

WHO - World Health Organization 2010. Global tuberculosis control. WHO report 2010, WHO, Geneva, 218 pp. 